\title{
Curso de Ciências Sociais: currículo, mercado e formação docente
}

\author{
Amaury Cesar Moraes*
}

\section{Resumo}

Neste artigo visamos discutir as tensões existentes entre a formação dada pelo curso de Ciências Sociais, consubstanciadas no currículo, e as demandas do exercício profissional, tendo em vista a realidade do mercado de trabalho. Embora os cursos sejam orientados em sua maioria para a formação do pesquisador, o efetivo exercício do profissional se dá no campo do magistério de ensino médio. Fica, então, desde sempre, um problema ainda não resolvido: um déficit na formação do professor e uma frustração da expectativa de ser um pesquisador. Sugerimos então uma revisão profunda do curso e das habilitações existentes. Quanto à formação docente, uma das habilitações possíveis, apresentamos uma análise preliminar da formação do professor em nível de graduação e pós-graduação a partir da discussão das relações entre o bacharelado e a licenciatura na formação de professores de Sociologia para o ensino médio, tomando como exemplo o caso da USP. Outra referência é a formação que ocorre na Pós-Graduação, na qual se amplia o divórcio entre pesquisa e ensino, aprofundando os problemas de formação de professores: desintegração, hierarquização, desproporção entre os cursos, resultando na formação deficiente de professores.

Palavras-chave: Currículo. Mercado de trabalho. Formação de professores.

* Doutor em Educação pela Universidade de São Paulo (USP). Professor do Departamento de Metodologia do Ensino e Educação Comparada da Faculdade de Educação da Universidade de São Paulo. 


\section{Introdução: currículo e mercado de trabalho}

Enfrentar uma questão dessas - relações entre currículo e mercado de trabalho - não é das mais simples na nossa área. Se pensássemos em engenharia, medicina ou direito - para ficar nas tradicionais carreiras de formação universitária -, não haveria o mesmo problema. Essas carreiras foram feitas sempre com uma integração clara e explícita entre currículo e mercado de trabalho. Em boa medida, o mercado de trabalho orientou tais carreiras e, portanto, o currículo. No nosso caso, ao contrário, o currículo se organizou à parte, alheio a uma possível relação com o mercado de trabalho. Mesmo se tomarmos o caso do primeiro curso de Ciências Sociais, da Escola Livre de Sociologia e Política (ELSP), datado de 1933, em que se tinha como objetivo a formação de quadros da burocracia pública e privada (LIMONGI, 1995a), vemos que a estrutura do curso e sua orientação tinham na pesquisa o seu principal esteio.

Acresce que a criação do curso na Faculdade de Filosofia Ciências e Letras (FFCL) da USP, em 1934, o segundo curso de Ciências Sociais do país, todo ele em princípio voltado para a formação de pesquisadores - "estudos desinteressados", "altos estudos", como se dizia então (ANTUNHA, 1984) -, profundou essa orientação. E mais: por um tempo a ELSP, na falta de cursos de pós-graduação na USP, foi responsável por esse nível de ensino, de certa forma fugindo ainda mais àquela proposta inicial de formar administradores públicos e privados. Por contingências da época, o curso da USP - n da FFCL, na verdade - acabou até se enveredando para uma profissionalização mal confessada: a formação de professores para o ensino secundário... (LIMONGI, 1995b; AZEVEDO, 1955) O certo é que os cursos de Ciências Sociais, com o passar do tempo, foram se afastando cada vez mais de uma preocupação com o mercado de trabalho e voltando-se para a formação de pesquisadores, o que, dada a

dificuldade de colocação para seus egressos, passou a funcionar quer como uma "formação geral sólida" no campo das Ciências Humanas, constituindo-se como uma segunda graduação para muitos, quer como reserva para reprodução dos próprios departamentos de Ciências Sociais.

A institucionalização da pós-graduação em fins dos anos 1960 ampliou ainda mais esse divórcio. É claro que muitos cursos incluem disciplinas e têm um discurso mais pragmático - é o caso de muitos cursos de instituições privadas -, mas o cerne do curso, isto é, o que domina o currículo, é ainda marcado por uma visão clássica de formação em Ciências Sociais, mais teórica que prática. Assim, quando se pensa em alguma alteração do currículo, esta, muita vez, está mais ligada a questões como evasão escolar do que a divergências com o que o mercado exige (MORAES, 2004; VILASBOAS, 2003). Talvez a formação para o magistério secundário ainda seja a mais efetiva relação que se 
possa entrever dos cursos e o mercado de trabalho, embora não fique clara a ideia de profissionalização: o magistério, para o egresso de Ciências Sociais, não é encarado como uma profissão, senão como uma ocupação, um meio de sobrevivência enquanto não se consegue o emprego para o qual se formou - pesquisador ou professor universitário (LENNERT, 2009). Mas é o caso das instituições privadas, que, após a aprovação da obrigatoriedade do ensino da Sociologia no nível médio, criaram cursos de licenciatura em Sociologia, ao arrepio da lei. ${ }^{1}$

Então temos que, na maioria dos cursos, a ideia de uma base sólida acabou se "solidificando" e tornando quase impossível uma revisão da estrutura curricular. Ademais, com o passar do tempo, a decadência acentuada dos cursos secundários levou a se ter a impressão de que o curso de graduação deveria prever, por meio da criação de mais disciplinas obrigatórias ou, quando é possível, de optativas, alguma forma de superação daqueles problemas gerados pela quase total falta de repertório ou base dos alunos egressos do secundário. Em outros cursos, essa ampliação do currículo se deveu a fatores bastante discutíveis, como arranjos internos para contentar o corpo docente - os professores entram para trabalhar com as disciplinas básicas, atuando com os novos alunos, e, depois de algum tempo, desejam se dedicar ao ensino de algo mais próximo de suas especialidades e pesquisas ou lecionar para alunos veteranos...

De certa forma, as dificuldades para relacionar currículo e mercado de trabalho são evidenciadas, mais do que nunca, quando se trata de discutir as relações entre bacharelado e licenciatura. Fica claro que não se pode avançar quase nada na formação de professores - ampliação do currículo da licenciatura - devido à carga excessiva do bacharelado. O antigo “3+1”, proposto em $1939^{2}$, hoje está por volta de "6+1" - se fizermos uma comparação entre o número de disciplinas ou créditos exigidos no bacharelado em relação à licenciatura.

Por outro lado, a formação no bacharelado ainda é basicamente teórica, predominando as disciplinas introdutórias das Teorias Antropológicas, Políticas e Sociológicas ou cursos monográficos que aprofundam ainda mais esse caráter teórico. $\mathrm{Na}$ maioria dos cursos, as disciplinas voltadas para a Metodologia de Pesquisa - Métodos e Técnicas de Pesquisa - são no máximo três, alguma delas, muitas vezes, versando sobre Filosofia da Ciência ou Aspectos Epistemológicos da Pesquisa Social, entre outros. É possível que haja alguma optativa sobre Métodos Quantitativos e Qualitativos, mas nada mais. E isso resultou na lei que criou a profissão de sociólogo ${ }^{3}$, que atribui somente ao bacharel a prerrogativa de ser sociólogo porque somente ele sabe fazer pesquisa social.

Neste sentido, restam ainda três aspectos para serem debatidos: 
1. O sociólogo formado no bacharelado de Ciências Sociais está preparado para ser um pesquisador ou um gestor público (segundo o neologismo em moda)? Essa questão é importante, porque, enquanto o bacharelado se define pela formação de pesquisador, quando existe o cargo de sociólogo na administração pública - que no Brasil não existe na administração privada! -, quase nunca se lhe oferece a função de pesquisador. No máximo será um analista de pesquisas ou um membro de uma equipe multidisciplinar para a implantação de alguma política pública ou gestão de conflitos até das mais prosaicas das relações entre governo e população. Quando não o confundem com profissionais de Assistência, Serviço e Promoção Social;

2. Quando pensamos em currículo, referimo-nos ao Ministério da Educação (MEC) e quando pensamos em mercado de trabalho, referimo-nos ao Ministério do Trabalho (MTE). Assim, as legislações também muitas vezes se tornam esquizofrênicas, de modo que uma define, por exemplo, Diretrizes de Cursos, e a outra atuação e prerrogativas dos formados naqueles cursos, de maneira nem sempre coerente ou minimamente complementar;

3. Com relação a essas fontes de legitimação e legalização, temos, por um lado, como agentes de influência e mesmo de ação, professores universitários - MEC -, e, por outro, lideranças ou representações sindicais - MTE. Aqui também se produz uma dissonância, pois, se há alguns anos, em vista da campanha pela obrigatoriedade do ensino de Sociologia na escola média, essas duas formas de corporação estiveram juntas, "tudo tomou seu lugar, depois que a banda passou" - foi tudo efêmero ou ocasional. Passado o episódio, não há mais contato, ao menos entre as lideranças, de modo que a presença voluntária de um acadêmico a um evento sindical, ou de um representante sindical a um evento acadêmico, não tende a gerar maiores consequências - e, muita vez, como ocorreu conosco, dublê de diretor de sindicato e professor universitário, nem sempre era possível fundir essas duas representações, pois ou não havia espaço, ou havia impedimentos de fazê-lo.

Levando em consideração esses pontos, por que não pensar em curso/currículo que seja básico, no qual se proponham formas de especialização, dentre elas a licenciatura? Nesse sentido, valeria a pena avaliar como vem se dando o processo de formação de professores em nível de graduação e suas relações com a pós-graduação. 


\section{Formação docente: um campo tensionado na graduação e na pós-graduação}

Mudando o enfoque dos debates sobre ensino de Sociologia na escola média americana (high school), Michael DeCesare (2002) propõe a formação do professor como questão maior e decisiva para a melhoria do ensino da disciplina:

As reformas do passado dirigidas ao curso de Sociologia na escola média focaram em seus conteúdos e materiais didáticos usados. Esses esforços de reforma falharam quanto a produzir melhoria no curso de Sociologia no secundário. Este trabalho assume a posição de que as várias associações, nacional, regional e estadual, juntas como apoio de departamentos acadêmicos de Sociologia, devem, ao contrário, focar sobre o desenvolvimento da formação do professor de sociologia da escola média se eles estão falando sério sobre a melhoria da qualidade da Sociologia na escola média. (DeCESARE, 2002, p. 302).

Como se pode perceber, há semelhanças entre os problemas do ensino de Sociologia na escola média brasileira e na americana: não se trata nem de definir conteúdos nem de preparar materiais didáticos. Listas de conteúdos, pode-se fazer um sem número que não haverá aquela que seja a melhor, a mais adequada e muito menos a que resolva os problemas de formação do professor, que, aliás, se fosse bem formado, prescindiria de uma lista de conteúdos formulado sem a sua participação. Por outro lado, nunca nos faltaram livros didáticos, mesmo depois de 1942, quando a Sociologia deixou de ser obrigatória na escola secundária. Ainda que havendo uma demanda esparsa nesse nível de ensino e, sobretudo, permanente nos primeiros anos da graduação, muitos professores acabaram escrevendo livros, de um modo geral de caráter híbrido, uma vez que, por interesses editoriais ou para atender mesmo às necessidades dos alunos, esses livros visavam aos dois públicos, talvez causa de sua inadequação: ora muito elevados, ora muito rebaixados quanto à linguagem, organização de conteúdos e processo didático interno. Sobre esse caráter didático, também restam muitas questões (MEUCCI, 2000; TAKAGI, 2007; MORAES, 2003; SARANDY, 2004). Não sendo rigorosamente testados no ensino médio - só recentemente (2011) houve um programa oficial de avaliação desses livros -, tais livros são, em boa medida, resultado da prática de alguns ex-professores do ensino médio ou de encomendas a professores de universidades. Acontece aqui o mesmo em relação à lista de conteúdos: o professor bem formado usa os "livros didáticos" - no plural - em conjunto com a bibliografia a que teve acesso em sua formação. Acaba formulando, ele mesmo, o seu material didático, a partir de recortes dos livros existentes e daquela bibliografia de nível superior (TAKAGI, 2007). 


\section{Bacharelado X Licenciatura}

Acompanhando o debate sobre a obrigatoriedade do ensino de Sociologia na escola média, tenho sido testemunha do aparecimento cada vez mais frequente daquilo que podemos chamar de a questão da formação do professor. Primeiramente, vinha escondida na resistência de muitos membros da Academia quando se opunham ao ensino de Sociologia na escola média ou porque os alunos não tinham ainda maturidade ou capacidade de abstração suficientes para entender a complexidade e/ou sofisticação das análises e conceitos propostas pelas Ciências Sociais, ou porque os professores dariam cursos muito ruins, o que prejudicaria ainda mais a imagem das Ciências Sociais perante a Sociedade, sobretudo porque muitos dos que lecionam Sociologia nem são formados em Ciências Sociais: são Historiadores, Geógrafos, Filósofos e Pedagogos que completam cargas horárias com aulas de Sociologia.

À medida que nossos debates foram avançando e ultrapassando aquele espírito inicial de luta pela obrigatoriedade e tivemos de dar respostas mais consistentes e operacionais, começou a aparecer mais efetivamente também uma demanda específica, ora explicitada na alternativa imediata bacharelado e licenciatura, ora num objetivo mais complexo e fundamental: formação do professor de Sociologia para o ensino médio. E desde que começaram a ser implementadas as reformas da educação empreendidas pelo governo Fernando Henrique Cardoso (FHC), esse tema passou a ser mais geral, de toda a comunidade acadêmica, e uma questão absolutamente incontornável, dada pelas mais variadas pesquisas sobre educação ou pelos resultados de avaliações estaduais, nacionais ou internacionais (respectivamente: Sistema de Avaliação de Rendimento Escolar do Estado de São Paulo - SARESP, Sistema de Avaliação da Educação Básica - SAEB, Exame Nacional do Ensino Médio - ENEM, Programme for International Student Assessment - PISA).

Um diagnóstico constante, que é bom que se diga não se refere exclusivamente ao ensino de Sociologia, é sobre o divórcio entre o bacharelado e a licenciatura nas Universidades, em especial nas públicas - de um modo geral, nas instituições privadas, a licenciatura é o grande chamariz porque ofereceria um horizonte mais imediato e possível para os seus alunos, um lugar no mercado de trabalho: o magistério, em oposição a um incerto emprego como pesquisador. Aqui, é claro, essa diferença entre instituições públicas e privadas também poderia ser explorada, mas, dependendo da forma, apenas reforçaria uma divisão do mercado entre umas e outras, o que não dá conta do problema, pois se entende que as instituições públicas também devem formar para o magistério... 
Para o divórcio entre bacharelado e licenciatura haveria três soluções: a) aceitar o divórcio e oficiá-lo, separando as formações desde a entrada no vestibular; b) aceitar o divórcio e orientar todos os esforços para uma das habilitações; no caso das instituições públicas, ficar com o bacharelado, que teria mais a ver com os objetivos de formação de pesquisadores que essas instituições acabaram assumindo; c) não aceitar o divórcio, e aqui há uma subdivisão dessa hipótese: c1) não aceitar porque não existe, então se mantêm as coisas como estão; c2) não aceitar porque é possível solucionar o problema com rearranjos de currículos e filosofias.

\section{Bacharelado e Licenciatura: separados}

Consultando pelo menos dois cursos em que o bacharelado é separado da licenciatura Química e Matemática na USP (Vide sites junto às referências bibliográficas) - podemos perceber algumas diferenças substanciais:

- Química Licenciatura: carga horária de 2940 horas;

- Química Bacharelado: 3855 horas, cerca de 930 horas para disciplinas optativas eletivas;

- Até o $4^{\circ}$ semestre, o curso é o mesmo para bacharelado e licenciatura;

- A partir do $5^{\circ}$ semestre, aparecem disciplinas ditas pedagógicas, cursadas na Faculdade de Educação, e disciplinas orientadas para o ensino, no próprio Instituto de Química: Instrumentação para o Ensino de Química I a IV, perfazendo 360 horas, e História das Ciências, com 60 horas;

- Matemática Licenciatura: carga horária de 2850 horas;

- Matemática Bacharelado: 2235 horas.

No caso de Matemática, os cursos são bastante diversos, apenas contendo algumas disciplinas optativas, que os alunos devem fazer no próprio Instituto de Matemática e Estatística (IME), as quais compõem também a grade de disciplinas do bacharelado.

Apesar de as mudanças na licenciatura terem sido efetivadas há quase duas décadas e, juntamente com a Física, terem tido o caráter de "Experimental", não se tem informação suficiente sobre se os resultados são melhores ou piores do que anteriormente. O certo é que na oportunidade de uma reformulação das licenciaturas na USP, denominada de Programa de Formação de Professores da USP (2006), suas licenciaturas foram mantidas separadas dos bacharelados. E no período foi criado o curso de licenciatura em Química, separado do bacharelado, realizado no período noturno, embora 
continue a existir a modalidade "bacharelado + licenciatura" em Química, chamado de integral, no período diurno.

Comparando-se a estrutura dos cursos de Química, percebe-se claramente uma diferença de quantidade entre os dois cursos - cerca de 900 horas (o bacharelado é em período integral) - e poderse-ia concluir que a modalidade tradicional (bacharelado + licenciatura) é qualitativamente melhor do que a modalidade licenciatura noturno, levando-se em consideração as cargas horárias diversas, e que, no caso do bacharelado + licenciatura, a carga horária se eleva para mais de 4500 horas: 3855 horas (bacharelado $)+360$ horas licenciatura +300 horas estágio.

Já se comparando a estrutura dos cursos de Matemática, não se pode, à primeira vista, entender que tenha havido perdas em termos de qualidade, uma vez que nem as disciplinas básicas de um e de outro curso correspondem, são absolutamente direcionadas para a especificidade dos cursos, tornandoos incomparáveis; por outro lado, a licenciatura conta com cerca de 600 horas a mais do que o bacharelado, não constituindo mero acréscimo de disciplinas pedagógicas e estágio supervisionado. Nesse sentido, a licenciatura em Química e a licenciatura em Matemática na USP revelam-se modelos a serem estudados em profundidade, a fim de que se possam retirar deles informações para a proposição de cursos de licenciatura exclusivos.

\section{Bacharelado e Licenciatura: juntos, porém separados.}

Ainda seguindo o caso da USP, vamos encontrar o curso de Ciências Socais que segue o padrão mais convencional de um curso de "bacharelado + licenciatura". O bacharelado é a entrada dos alunos e a sua conclusão é a condição para a conclusão da licenciatura, pois não poderá ser licenciado sem ser bacharel. A licenciatura depende do bacharelado. Uma ideia sempre presente é que o bacharelado dá a formação sólida, de "conteúdo", para os alunos, futuros professores, e a licenciatura viria para "complementar", com a parte pedagógica, muita vez entendida como sendo a parte didática ou metodológica, a "forma".

A carga horária do bacharelado é de cerca de 2100 horas, à qual a licenciatura acrescentaria 360 horas de disciplinas e mais 300 horas de estágio supervisionado. Na reforma de licenciatura da USP (Programa de Formação de Professores, 2006), ficou estipulado que os cursos deveriam ter, já no bacharelado, pelo menos uma disciplina voltada para o ensino ou a educação que pudesse "fazer a ponte" com a licenciatura e coube, então, à Sociologia da Educação fazer este papel. 
É claro que para isso é necessário fazer-se uma revisão de programas e objetivos do que vem sendo tradicionalmente tratado nessa disciplina, que, embora possa se referir à educação em sentido amplo e rigoroso, não atende necessariamente às questões relativas, por exemplo, aos debates sobre conteúdos de ensino a serem desenvolvidos na escola média. Uma outra novidade, que vem atender ao disposto na legislação federal sobre a formação de professores, é a inclusão de 100 horas de estágio supervisionado no bacharelado, o que aparentemente estaria vinculado àquela disciplina sobre educação ou ensino. Em 2002, o Conselho Nacional de Educação baixou resolução (Resolução $\mathrm{CNE} / \mathrm{CP}$ 2/2002) ampliando as horas de prática de ensino de 300 para 400 horas.

Assim descrito, parece não haver problemas, mas, ao contrário, uma integração das formações. No entanto, se considerarmos mais de perto, veremos que a formação para professor de Sociologia, ou Metodologia do Ensino de Ciências Sociais (MECS) I e II, corresponde a 120 horas. As 300 horas de prática de ensino são divididas hoje em 60 horas de estágio em Didática, Psicologia da Educação e Política e Organização da Educação Básica Brasileira (POEB); das 240 horas restantes, para o estágio propriamente dito vão 120; e às mesmas Metodologias de Ensino, teóricas, correspondem 120 horas (que assim têm duplicada a sua contagem: 120 horas no histórico escolar, como disciplina, e 120 horas de prática de ensino). Com a mudança da licenciatura, todas as 300 horas seriam destinadas a estágios: gestão, projetos integrados e projetos específicos (o que até o momento não foi efetivado).

Para além dessa contabilidade, vamos nos ater ao que se refere especificamente à formação do Professor de Sociologia, as $120 \mathrm{~h}$ de MECS I e II. Caberia ao professor responsável por essas disciplinas, além da supervisão do estágio - feito em escolas de nível médio, de preferência públicas -, cuidar de um conjunto de dimensões que dariam conta propriamente de uma formação inicial:

- Discussão e orientação para organização dos conteúdos a serem ensinados e bibliografia correspondente;

- Orientação sobre organização do material didático e/ou análise dos livros didáticos e bibliografia correspondente;

- Orientação sobre processos e instrumentos de avaliação e bibliografia correspondente;

- Apresentação e discussão sobre metodologias do ensino e bibliografia correspondente;

- Apresentação e discussão sobre recursos de ensino e bibliografia correspondente;

- Demonstrações "práticas" de cada tema e cruzamento de alguns deles;

- Orientação para elaboração de relatórios de estágio e avaliação dos relatórios;

- Orientação para elaboração de planos de ensino e planos de aula e avaliações deles; 
- Discussão de outras questões: currículo, legislação, disciplina ou relação aluno/professor, pesquisa educacional, pesquisa sobre Ensino de Sociologia, profissionalização/sindicalização, atuação no coletivo da comunidade escolar, etc.

Entendemos que o tempo destinado a tudo isso é extremamente exíguo - 120 horas de MECS I e II - e que alguns desses itens poderiam ser tratados com mais propriedade por outras (novas) disciplinas que se referissem à legislação específica e à história da disciplina escolar, ao currículo, etc. Todo o problema é que a licenciatura não pode ser ampliada, sobretudo porque a carga horária do bacharelado é extensa demais, quase fechando cada um dos 8 semestres do curso, restando pouca margem para os alunos fazerem as 6 disciplinas da licenciatura junto com o bacharelado e no mesmo turno desse. A solução aqui seria ampliar um pouco mais o currículo da licenciatura, oferecendo uma formação sólida também, com consequente redução do bacharelado ou ampliação do curso como um todo, digamos, mais um ano, como se fosse uma especialização. Contra essa proposta há uma tendência à redução dos prazos dos cursos.

\section{Bacharelado e licenciatura ou pesquisa e ensino}

Tradicionalmente o que tem sido tomado como critério para a separação entre bacharelado e licenciatura é a orientação para a formação profissional. O bacharelado em Ciências Sociais, mas não só, tem por principal senão único objetivo formar pesquisadores; a licenciatura explicitamente estaria voltada para a formação de professores, para o ensino. Em que medida o currículo do bacharelado estaria mais voltado para a pesquisa? Além das chamadas Metodologias de Pesquisa ou Métodos e Técnicas de Pesquisa I, II e III, que outras disciplinas cumpririam essa finalidade? Estatística, uma disciplina mais extensa antigamente, foi tendo sua carga horária reduzida quer em vista dos chamados métodos qualitativos, etnográficos, quer por uma resistência dos alunos que, buscando as Ciências Humanas, fugiam às Ciências Exatas e apresentavam muita dificuldade ao depara-se novamente com esse tipo de disciplina. É claro também que se possa aludir que todo o conjunto das disciplinas constantes nos programas de Ciências Sociais esteja voltado para a pesquisa, embora de modo implícito, o que garantiria a alguém, formado em bacharelado ou licenciatura, uma base razoável para o exercício da pesquisa.

Por outro lado, parece que a licenciatura, ou as disciplinas pedagógicas, incluindo aí a Metodologia do Ensino, careceria(m) dessa orientação "para a pesquisa", ocupando-se exclusivamente 
de "métodos" e "técnicas" de ensino. Acontece que, particularmente nas instituições públicas, até nas faculdades de educação a orientação para a pesquisa é uma obrigação incontornável, de modo que os professores dessas disciplinas também são pesquisadores e as disciplinas também acabam tendo essa dupla finalidade: prática de ensino e prática de pesquisa. Mas também devemos nos lembrar de que algumas dessas disciplinas - como as Metodologias ou Práticas de Ensino -, em muitas instituições, são dadas nos próprios departamentos de Ciências Sociais, e não em faculdades de educação, estando os professores sujeitos às regras da dinâmica desses departamentos, que impõem a pesquisa como uma condição de contrato etc. Pode-se pensar que a ampliação da licenciatura daria maiores e melhores condições para que se desenvolvessem mais explícita e intensamente a pesquisa nessa área, que tem ficado carente por conta daquela divisão e abandono da Sociologia da Educação para o campo da Pedagogia (LÜDKE,1991).

A partir da tese de doutoramento de Ileizi Silva (2006), que faz um estudo comparativo e histórico dos cursos de Ciência Sociais em duas instituições de ensino do Paraná - Universidade Federal do Paraná (UFPR) e Universidade Estadual de Londrina (UEL) -, percebemos que, enquanto a UFPR repete em boa medida a estrutura da USP, a UEL busca fugir desse padrão, ao instituir cursos separados ou com formação especializada a partir da segunda metade de sua duração. No entanto, ao observarmos mais de perto os currículos dos cursos - bem informados pelos quadros trazidos pela autora -, percebemos que as diferenças ainda são bastante reduzidas em termos de especialização para a pesquisa (bacharelado) e para o ensino (licenciatura). Fora uma Metodologia de Pesquisa a mais, outras disciplinas do bacharelado ainda são, aparentemente, teóricas (a menos que se lhes aplique aquela interpretação de que são teórico-metodológicas, o que é discutível em termos de prática efetiva). É possível - e isso é imponderável quando se opera apenas com análise de currículos - que os cursos realmente se orientem para uma coisa ou outra no seu cotidiano, dependendo das idiossincrasias de professores e alunos. Mas aí precisaríamos de uma pesquisa que, mais que uma pesquisa, fizesse uma avaliação dessas formações específicas em termos de resultados. Também se pode pensar, então, que a licenciatura faça diferença com os projetos criados para efetivar o ensino, como é o caso dos chamados "laboratórios de ensino". Estes também estão a merecer um estudo mais aprofundado, pois temos ficado nos relatos e propostas que, de um modo geral, são laudatórios e pouco críticos (MORAES, 2009). 


\section{Formação Docente na Pós-Graduação}

De todos os níveis de ensino, a Pós-Graduação parece ter sido o que obteve maiores êxitos (DURHAM, 2005). São cursos mais bem estruturados, mais bem consolidados, mais bem avaliados, no duplo sentido da expressão. No entanto, a Pós-Graduação é orientada, no seu formato stricto sensu, que é a modalidade mais legitimada, para a pesquisa. Por um lado, porque não se requer mesmo nenhuma "formação docente" para os professores de nível superior. A própria Lei de Diretrizes e Bases da Educação Nacional (LDBEN, Lei 9394/1996), por exemplo, dispensa a prática de ensino na formação docente para a educação superior (art. 65). Entende-se, então, que a formação para a pesquisa é condição necessária e suficiente para ser professor de instituições superiores, podendo os títulos de mestre (o que não significa mestre-professor, mas muito mais mestre-pesquisador) e de doutor ser o bastante para se inscrever em concursos públicos para professor de ensino superior. Essa orientação para a pesquisa, que deveria ser uma característica positiva, pois ninguém ensina o que não sabe e ninguém nasceu sabendo, tornou-se com o tempo um mal ao promover uma hierarquização do campo e um divórcio em relação ao ensino. Acresce que em nosso campo - Ciências Sociais - o abandono das questões de educação para os pedagogos, conjugado com essa orientação para a pesquisa, produziu ainda um efeito mais deletério: as pesquisas sobre ensino de Sociologia ou Ciências Sociais, quando existiam, eram praticadas no campo da educação. Só muito recentemente têm sido abertos espaços no âmbito da Pós-Graduação das Ciências Sociais para essas pesquisas, assim mesmo enfocando processos sociais de institucionalização da disciplina Sociologia no ensino médio. Quando o objeto são recursos didáticos ou metodologia do ensino, essas pesquisas devem ficar adstritas a Faculdades de Educação; a história da disciplina, a análise de currículos, a organização de cursos, para serem aceitos em Programas de Pós-Graduação como objetos de pesquisa, devem atender àquela característica de “institucionalização". Quase nada se avançou num cruzamento entre questões de metodologia de pesquisa e metodologia do ensino (MORAES, 2003). Não é o que vem ocorrendo em outras áreas, por

exemplo, entre as Ciências da Natureza, que desenvolvem há décadas pesquisas sobre elaboração de conceitos, resolução de problemas, construção de hipóteses, etc., visando a uma "alfabetização científica", quer aproximando-se de teorias do ensino, de fundamentação psicológica (psicogenética, socioconstrutivismo, etc.) quer buscando embasamento em estudos da linguagem (Bakhtin), quer permanecendo nos seus limites ou nas iluminações que a Filosofia e a História das Ciências podem 
providenciar. Encontramos na tabela de áreas da Coordenação de Aperfeiçoamento de Pessoal de Nível Superior (CAPES) e Conselho Nacional de Desenvolvimento Científico e Tecnológico (CNPq), por exemplo, essas duas áreas: Educação e Ensino, esta última criada inicialmente como Ensino de Ciências, com a divisão da área maior Educação, tendo como principal razão a concorrência por verbas para financiamento de pesquisas.

\section{Inconclusões}

Sobre a formação de Professores de Sociologia ou Ciências Sociais para o ensino básico ou superior, continuamos ainda com alguns preconceitos ou concepções remanescentes de uma época de ouro, marcada por elitismos: saber o conteúdo é suficiente para saber ensinar; saber pesquisar é suficiente para saber ensinar; educação e ensino são questões para pedagogos; dominar a teoria é dominar a prática; o bacharelado dá uma sólida formação, a licenciatura aplica-lhe um verniz pedagógico, o que é suficiente; ser pesquisador é fruto de um aprendizado, ser professor é um dom ou vocação. Permanece em boa medida a blague que se repete nos "centros de pesquisa" das universidades: "quem sabe pesquisa; quem não sabe, ensina; e quem não sabe ensinar, vira quadro da burocracia acadêmica ou do movimento sindical".

\section{Notas}

1 O Parecer CNE/CES 492/2001, que institui as Diretrizes Curriculares Nacionais para Cursos de Graduação em Ciências Sociais, tem como primeiro princípio "propiciar aos estudantes uma formação teórico-metodológica sólida em torno dos eixos que formam a identidade do curso (Antropologia, Ciência Política e Sociologia)", o que impediria a criação de cursos de Sociologia somente.

${ }^{2}$ Decreto-Lei n. 1.190, de 4 de abril de 1939. Dá organização à Faculdade Nacional de Filosofia (Diretrizes para os Cursos de Licenciatura).

${ }^{3}$ Lei n. 6888, de 10 de dezembro de 1980, regulamentada pelo Decreto n. 89531, de 5 de abril de 1984.

\section{REFERÊNCIAS}

ANTUNHA, Heládio. C. G. Saudação ao Professor Paul Arbousse-Bastide. R. Fac. Educ. 10(2) p. 317322, São Paulo: FEUSP, 1984.

AZEVEDO, Fernando. Discurso de Encerramento do I Congresso Brasileiro de Sociologia, Anais do I Congresso Brasileiro de Sociologia, p. 53-71, São Paulo: SBS,1955.

BRASIL. Lei n. 9.394, de 20 de dezembro de 1996. Estabelece as Diretrizes e Bases da Educação Nacional. Diário Oficial [da] República Federativa do Brasil, 23 dez. 1996, p. 27833. 
DeCESARE, Michael A. - The lesson to be learned: the past troubles and future promise of teaching high school Sociology. Teaching Sociology, v. 30, july, p. 302-316, 2002.

DURHAM, Eunice R. A pós-graduação em Ciências Sociais. In: MARTINS, C. B. (Org.). Para onde vai a Pós-graduação em Ciências Sociais no Brasil, Bauru: EDUSC, 2005.

LENNERT, Ana Lucia. Professores de Sociologia: relações e condições de trabalho. 2009, $129 \mathrm{f}$. Dissertação (Mestrado em Educação) Faculdade de Educação da Universidade de Campinas, Campinas: Unicamp, 2009.

LIMONGI, Fernando P. A Escola Livre de sociologia e Política em São Paulo. In: MICELI, Sergio (Org.). História das Ciências Sociais no Brasil. v. 2. São Paulo: Fapesp, 1995.

LIMONGI, Fernando P. Mentores e clientelas da Universidade de São Paulo. MICELI, Sergio (Org.). História das Ciências Sociais no Brasil. v. 2. São Paulo: Fapesp, 1995.

LÜDKE, Menga Entrevista com Pierre Bourdieu. Teoria e Educação no. 3, p. 3-8, Porto Alegre: Pannonica, 1991.

MEUCCI, Simone. A Institucionalização da Sociologia no Brasil: os primeiros manuais e cursos. 2000, 157f. Dissertação (Mestrado em Sociologia). Instituto de Filosofia e Ciências Humanas Universidade de Campinas, Campinas, 2000.

MORAES, Amaury C. Licenciatura em ciências sociais e ensino de sociologia: entre o balanço e o relato. Revista Tempo Social, São Paulo, v. 15, n. 1, p. 05-20, 2003.

MORAES, Amaury C. O ensino de Ciências Sociais sob novas diretrizes. In: REUNIÃO ANUAL DA ANPOCS, 28, FÓRUM FILOSOFIA E SOCIOLOGIA NO ENSINO MÉDIO - ROMPENDO PRECONCEITOS, Caxambu, MG, 28 out. 2004. (inédito).

MORAES, Amaury C. Laboratórios de Ensino de sociologia: um debate necessário, comunicação apresentada. In: CISO - ENCONTRO DE CIÊNCIAS SOCIAIS DO NORTE E NORDESTE, sessão especial Laboratórios de Ensino de Sociologia, Universidade Federal Rural de Pernambuco, Recife, 2009 (inédito).

SARANDY, Flávio M. S. A sociologia volta à escola: um estudo dos manuais de Sociologia para o ensino médio no Brasil. 2004, 142 f. Dissertação (Mestrado em Sociologia) - Universidade Federal do Rio de Janeiro. Rio de Janeiro: UFRJ, 2004.

SILVA, Ileizi L.F. Das fronteiras entre ciência e educação escolar - as configurações do ensino das Ciências Sociais, no estado do Paraná (1970-2002). 2006. 311 f. Tese (Doutoramento em Sociologia) Faculdade de Filosofia Letras e Ciências Humanas - Universidade de São Paulo, São Paulo: FFLCHUSP, 2006.

TAKAGI, Cassiana T. T. Ensinar sociologia: análise dos recursos didáticos. Dissertação (Mestrado em Educação). 2007. 277 f. Faculdade de Educação da Universidade de São Paulo, São Paulo: FEUSP, 2007. 
VILAS-BOAS, Gláucia. Currículo, iniciação científica e evasão de estudantes de Ciências Sociais, Revista Tempo Social, São Paulo - SP, v. 15, n. 1, p. 45-62, 2003.

Matemática bacharelado. Disponível em:

$<$ https://uspdigital.usp.br/jupiterweb/listarGradeCurricular?codcg=45\&codcur $=45031 \&$ codhab=1\&tipo $=\mathrm{N}>$. Acesso em: 21 jun. 2016.

Matemática licenciatura. Disponível em:

$<$ https://uspdigital.usp.br/jupiterweb/listarGradeCurricular?codcg=45\&codcur $=45024 \& \operatorname{codhab}=1 \&$ tipo $=\mathrm{N}>$. Acesso em: 21 jun. 2016.

Química licenciatura. Disponível em:

$<$ https://uspdigital.usp.br/jupiterweb/listarGradeCurricular?codcg=46\&codcur=46300\&codhab=204\&ti po $=\mathrm{N}>$. Acesso em: 21 jun. 2016. 
Social Sciences Course Curriculum, the

\section{Labor Market and Teacher Education}

\section{Abstract}

In this article we discuss the tensions between the education provided by the social sciences course, substantiated in the curriculum, and the demands of professional practice, considering the reality of the labor market. Although the courses are geared mostly to educating researchers, most graduates work as high school teachers. Thus, an unsolved problem remains: deficiencies in teacher education and frustration to the expectation of becoming a researcher. We thus suggest a thorough review of the course and the skills it now seeks to develop. Regarding teacher education, one of the possible professions for which the course prepares students, we present a preliminary analysis of teacher education at the undergraduate and graduate level based on a discussion of the relationship between a bachelor's degree (for researchers) and teacher accreditation in high school sociology, using as an example the case of the University of São Paulo (USP). Another reference is the education provided in the graduate course, in which the divorce between research and teaching is wider, deepening the problems of teacher education: disintegration, hierarchization, imbalance between the courses, which resul in poor teacher education.

Keywords: Curriculum. Labor market. Teacher education.
Cours de Sciences Sociales: programme de cours, marché du travail et formation des enseignants

\section{Resumé}

Dans cet article, nous visons à discuter les tensions entre la formation donnée au cours de Sciences Sociales, énoncées dans le programme d'études, et les exigences de la pratique professionnelle, compte tenu de la réalité du marché du travail. Bien que les cours soient orientés principalement à la formation du chercheur, l'exercice effectif du professionnel a lieu dans le domaine de l'enseignement de l'école secondaire. Il est alors toujours un problème pas résolu: un déficit de formation des enseignants et une frustration d'attendre d'être chercheur. En ce qui concerne la formation des enseignants, l'une des qualifications possibles, nous présentons une analyse préliminaire de la formation des enseignants au niveau de premier cycle et des cycles supérieurs de la discussion de la relation entre B.A. et un diplôme en formation des enseignants de la sociologie pour le lycée, en prenant comme exemple le cas de l'USP. Une autre référence est la formation qui a lieu dans le Graduate, qui élargit le divorce entre la recherche et l'enseignement, l'approfondissement des problèmes de formation des enseignants: l'effritement, la hiérarchie, la disproportion entre les cours, ce qui entraîne la formation insuffisante des enseignants.

Mots-clés: Programme. Le marché du travail. La formation des enseignants.

Enviado em: 25/07/2016

Versão final enviada em: 10/10/2016

Aprovado em: 11/10/2016

\section{Amaury Cesar Moraes}

E-mail: acmoraes@usp.br 